\title{
Massive thrombosis in an infant with suspected nephrocalcinosis: case report and literature review
}

\author{
MAGDALENA KOWALEWSKA-MŁOT ${ }^{l}$, PIOTR SKRZYPCZYK ${ }^{l}$, GRAŻYNA KRZEMIEN ${ }^{l}$, \\ MICHAE BRZEWSKI ${ }^{2}$, ANNA KLUKOWSKA ${ }^{3}$, MAEGORZATA PAŃCZYK-TOMASZEWSKA ${ }^{l}$ \\ 'Department of Pediatrics and Nephrology, Medical University of Warsaw, Warsaw, Poland \\ ${ }^{2}$ Department of Pediatric Radiology, Medical University of Warsaw, Warsaw, Poland \\ ${ }^{3}$ Department of Pediatrics, Hematology and Oncology, Medical University of Warsaw, Warsaw, Poland
}

\begin{abstract}
Introduction: Perinatal period is characterized by an increased risk of thrombosis due to low resources and limited compensatory capacity of the coagulation system in early stages of life.

Case report: We report a case of a second pregnancy female infant born at 39 weeks by caesarean section, due to pre-labor rupture of membranes, with body weight of 3,570 g and Apgar score 10. The pregnancy was complicated by hypothyroidism, uterine myoma, urinary tract infections, and mother's appendectomy at $16 \mathrm{Hbd}$. At 3 months, the girl was admitted to our hospital due to kidney calcifications, which were incidentally found during ultrasound scan. In laboratory workup, no abnormalities in calcium and phosphate homeostasis were detected. However, in ultrasound scan, linear calcifications along pyramids were visualized in both kidneys. Due to atypical location of nephrocalcinosis, Doppler scan was performed, showing lack of visible blood flow from renal veins to inferior vena cava (IVC), with compensatory flow from renal veins to paravertebral plexuses, and IVC obliteration with a massive calcification in the hepatic section. Magnetic resonance confirmed obliteration of IVC and common iliac veins, segmental dilatation of IVC, and compensatory blood flow from kidneys and lower limbs to paravertebral plexuses. Clinical picture and formation of collateral circulation suggested intrauterine thrombosis. Congenital thrombophilia was excluded in laboratory examination.

Conclusions: The differential diagnosis of calcifications in renal parenchyma (nephrocalcinosis) should include renal vein thrombosis. Massive fetal and perinatal thrombosis can be asymptomatic due to high ability to form collateral circulation at the early stage of life.
\end{abstract}

Key words: neonate, nephrocalcinosis, inferior vena cava thrombosis, renal vein thrombosis, fetal thrombosis, developmental hemostasis.

(Cent Eur J Immunol 2020; 45 (3): 355-360)

\section{Introduction}

Coagulation factors are produced by the fetus, which could be detected as early as after 10 weeks of pregnancy [1-3]. The concentration of coagulation factors in the fetus increases gradually [4] and is lower in premature babies, compared to full-term newborns and older children [2, 3]. After delivery, the concentration of vitamin K-dependent coagulation factors (II, VII, IX, and X) and contact factors (XI, XII, prekallikrein, high molecular weight kininogen) are approximately $25-70 \%$ of the concentration in adults [3], while the concentrations of factors V, VIII, XIII, and fibrinogen are comparable to those found in adults [5, 6]. The immaturity of coagulation proteins at this age is compensated by low (approx. 50\% of adults) concentration of inhibitors of the coagulation system (protein $\mathrm{C}$, protein $\mathrm{S}$, antithrombin, and heparin II cofactor) and reduced plasma fibrinolytic activity $[2,3,7]$. At the early stage of life, the coagulation system has a little of resources and compensatory capacity in response to external factors, resulting in an increased tendency for both thrombosis and bleeding $[2,3]$. In most children, coagulation proteins reach normal levels at nearly 1 year of age $[3,6]$.

Fetal, perinatal thrombosis is a rare event mainly associated with risk factors (Table 1). The most common risk factor is the presence of vascular (especially central and umbilical) catheters $[1,3,8,9]$. The most frequent localization of thrombosis is renal vein with or without an involvement of inferior vena cava (IVC), central nervous system veins, and portal or mesenteric vein $[1,2,10]$. Re-

Correspondence: Piotr Skrzypczyk, MD, PhD, Department of Pediatrics and Nephrology, Medical University of Warsaw, 63A Żwirki i Wigury St., 02-091 Warsaw, Poland, e-mail: pskrzypczyk@wum.edu.pl Submitted: 23.04.2020; Accepted: 6.07.2020 
Table 1. Risk factors for perinatal thrombosis, modified according to [2, 3, 8, 10, 17, 19, 20]

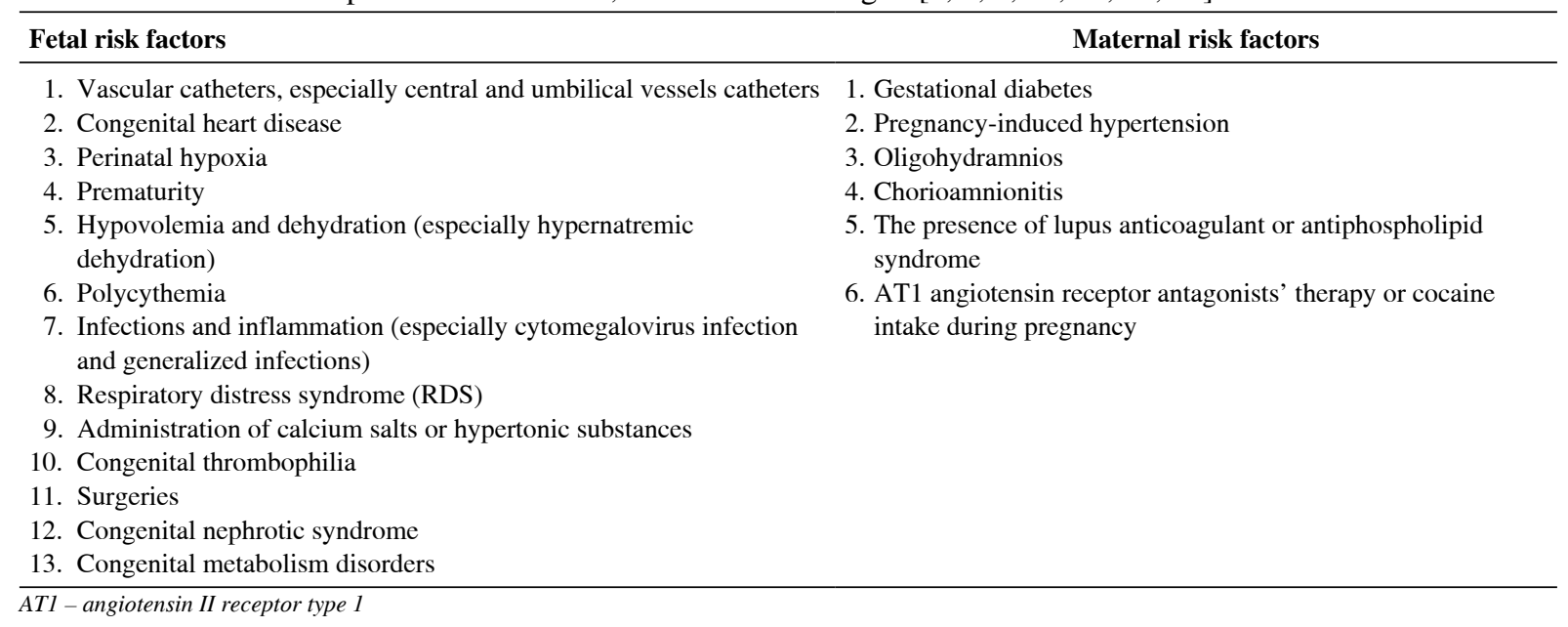

nal vein and IVC thrombosis in the perinatal period occur with an estimated frequency of 2.2 per 100,000 live births and have a diverse clinical manifestation [2,3]. Due to the compression by the arteries, thrombosis is the most commonly observed in the left renal vein $[11,12]$. The course of renal vein thrombosis can be acute, with the classic triad of symptoms, including hematuria, palpable abdominal resistance, and thrombocytopenia, which may be accompanied by anemia $[3,8,13]$. At times, however, the course of thrombosis is asymptomatic, with its consequences revealed in long follow-up [3, 13]. Particularly severe course is observed in bilateral renal vein thrombosis $(25 \%$ of cases), which increases the risk of acute kidney injury that often requires renal replacement therapy and may result in child's death [1-3]. Isolated IVC thrombosis without renal vein involvement is most often associated with the use of vascular catheters (inserted through the umbilical vein or veins of the lower extremities). Thrombosis in this location may be asymptomatic or manifest as swelling and bruising of the extremities and lower body [8].

The aim of this study was to present a case of an infant with a massive abdominal vein thrombosis, who was admitted to our center with a preliminary diagnosis of nephrocalcinosis.

\section{Case report}

We present a case of a female infant born from second pregnancy (first pregnancy resulted in miscarriage in $20^{\text {th }}$ week of gestation after abdominal injury), mother of Latin American descent, father of Polish origin. Negative family history of kidney diseases, calcium and phosphate homeostasis disorders, urolithiasis, systemic diseases, and thrombosis. The pregnancy was complicated by hypothyroidism, uterine myoma, urinary tract infections, and appendectomy at $16^{\text {th }}$ week of gestation. Fetal ultrasound scan (US) performed repeatedly did not show any abnormalities, with normal image of the kidneys. The baby was born by caesarean section due to pre-labor rupture of the membranes, with a body weight of $3,570 \mathrm{~g}$ and Apgar score of 10 . The adaptation period was normal; the girl was vaccinated according to routine vaccination schedule and breastfed. At the age of 2 months, she was hospitalized in the city hospital due to bronchiolitis. The abdominal US showed kidneys $45 \mathrm{~mm}$ long with an abnormal image of the renal columns, with numerous hyperechogenic foci. Nephrocalcinosis was suspected and the infant was referred to our hospital. The girl was admitted at the age of 3 months in good general condition, no physical abnormalities, and arterial blood pressure of 77/36 mm Hg. Laboratory examination were as follows (reference ranges in brackets): WBC $8.06 \times 10^{3} / \mu \mathrm{l}(5.7-17), \mathrm{RBC} 4.09 \times 10^{6} / \mu \mathrm{l}$ (3.2-4.3), PLT $415 \times 10^{3} / \mu \mathrm{l}(250-550), \mathrm{CRP}<0.5 \mathrm{mg} / \mathrm{dl}$ $(\leq 1.0)$, creatinine $0.2 \mathrm{mg} / \mathrm{dl}(0.2-0.4)$, urea $14.0 \mathrm{mg} / \mathrm{dl}$ (2.2-27.8), calcium $10.5 \mathrm{mg} / \mathrm{dl}$ (7.7-11.5), phosphorus $7.2 \mathrm{mg} / \mathrm{dl}$ (2.5-7.0), alkaline phosphatase $281 \mathrm{U} / 1$ (80345), 25(OH)D $20.4 \mathrm{ng} / \mathrm{ml}$ (20-50), parathyroid hormone $7.7 \mathrm{pg} / \mathrm{ml}$ (12-95); urinary crystallization ratio: calcium : creatinine ratio $0.43(<0.81)$, phosphorus : creatinine ratio 0.85 (0.3-1.2), magnesium : creatinine ratio 0.55 $(>0.1)$, magnesium : calcium ratio $1.29(0.8-1.3)$. The results of urinalysis were within the normal range. In the ultrasound scan, numerous hyperechogenic foci in both kidneys were observed and nephrocalcinosis was suspected. Vitamin $\mathrm{D}_{3}$ supplementation was discontinued. After 3 months, serum phosphorus normalized $(6.0 \mathrm{mg} / \mathrm{dl})$, and $25(\mathrm{OH}) \mathrm{D}$ level was slightly below normal range $(19.8 \mathrm{ng} / \mathrm{ml})$. US showed right kidney $54 \mathrm{~mm}$ long, left kidney $62 \mathrm{~mm}$ long, linear calcifications along the pyramids visible in both kidneys, more lesions in the left kidney (Figs. 1A, 1B, 1D). Doppler scan showed lack of visible blood flow from the renal veins to IVC, with compensatory flow from the renal veins to the paravertebral plexuses; IVC obliteration, with a massive calcification in the hepatic section (Fig. 1C); minor linear calcifications in the liver caudate lobe at the point of contact with IVC. The connection 

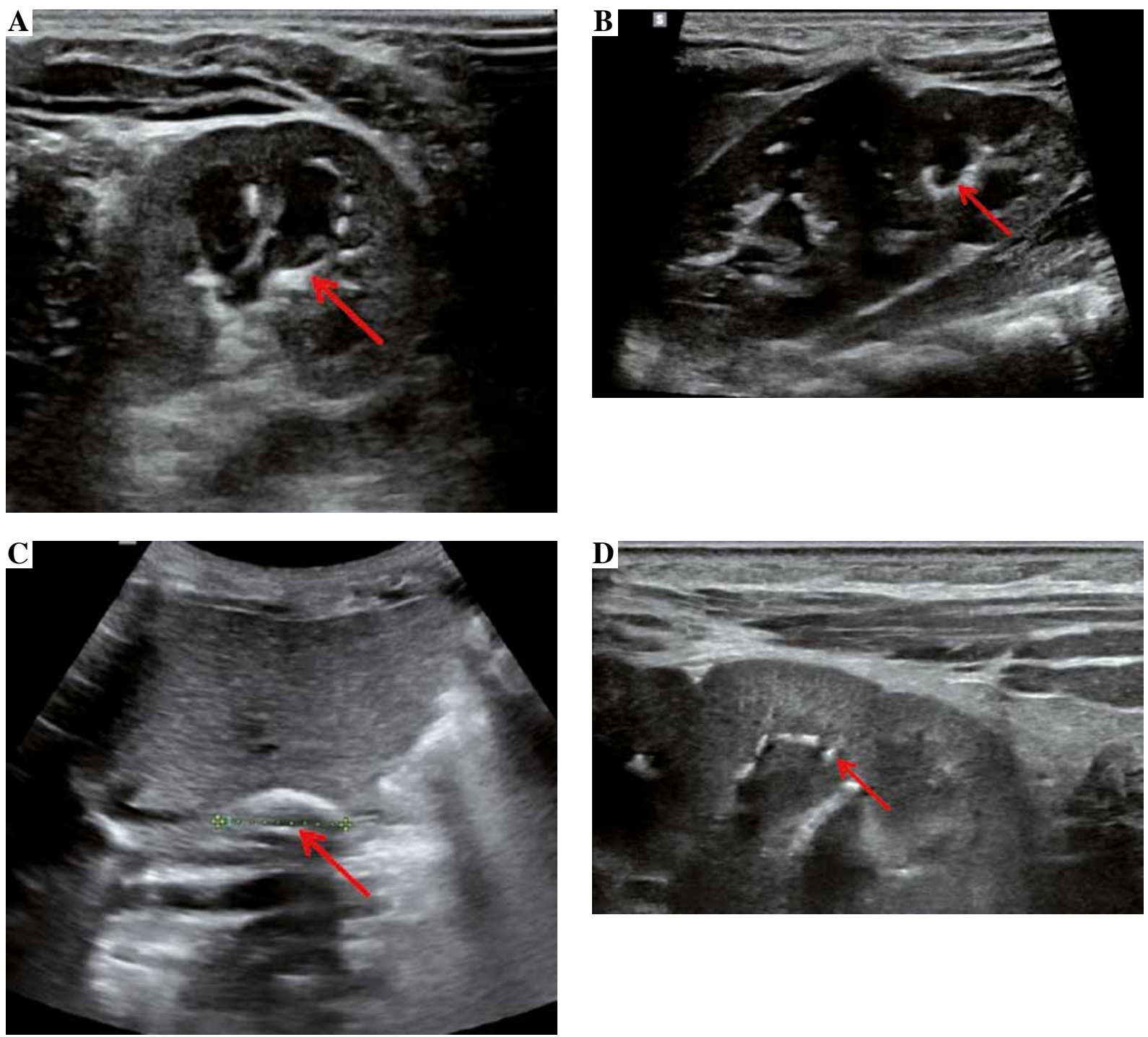

Fig. 1. Ultrasonography of the abdomen. A, B, D) In both kidneys, linear calcifications along the pyramids. C) IVC occlusion with a massive calcification in the hepatic segment

between IVC and common iliac veins were not visible. The image suggested the history of extensive venous thrombosis. Magnetic resonance (MR) revealed no contrast flow in the iliac veins and IVC, compensatory venous outflow from the lower limbs and from the kidneys to the paravertebral plexuses (Fig. 2); in IVC, a segmental dilatation of $11 \times 7 \mathrm{~mm}$ over a length of $23 \mathrm{~mm}$ spatially coincident with calcification described in the ultrasound scan. The results of coagulation system were as follows: INR 1.01 (0.9-1.2), kaolin-cephalin clotting time $34.62 \mathrm{~s}$ (28-40), fibrinogen $1.77 \mathrm{~g} / \mathrm{l}(1.80-3.50)$, homocysteine $6.92 \mu \mathrm{mol} / \mathrm{l}$ (3.70-13.90), antithrombin III 96.3\% (75-125), protein C 61\% (50-125), protein S 67.36\% (50-125), D-dimers $6893.06 \mu \mathrm{g} / 1$ (0-550). Leiden factor $\mathrm{V}$ mutation and c. $20210 \mathrm{G}>$ A prothrombin gene mutation were excluded. Due to the increased concentration of D-dimers and obliter- ated IVC, low-molecular-weight heparin was administered at the therapeutic dose (nadroparin, $100 \mathrm{IU}$ antiXa/kg once daily, subcutaneously). Anticoagulation was continued for 4 months. After a month of anticoagulation, D-dimer levels came back to normal $(433.54 \mu \mathrm{g} / \mathrm{l})$. Ultrasound scan performed at the age of 10 months showed: right kidney $60 \mathrm{~mm}$ long, left kidney $68 \mathrm{~mm}$ long, image of the venous system as in the previous study. The girl is currently 2 years old, develops according to age, and is under the care of a nephrology and hematology clinic. Obliterated venous vessels did not recanalize.

\section{Discussion}

Calcifications within the renal parenchyma (nephrocalcinosis) can include both the core and medulla (Table 2). 

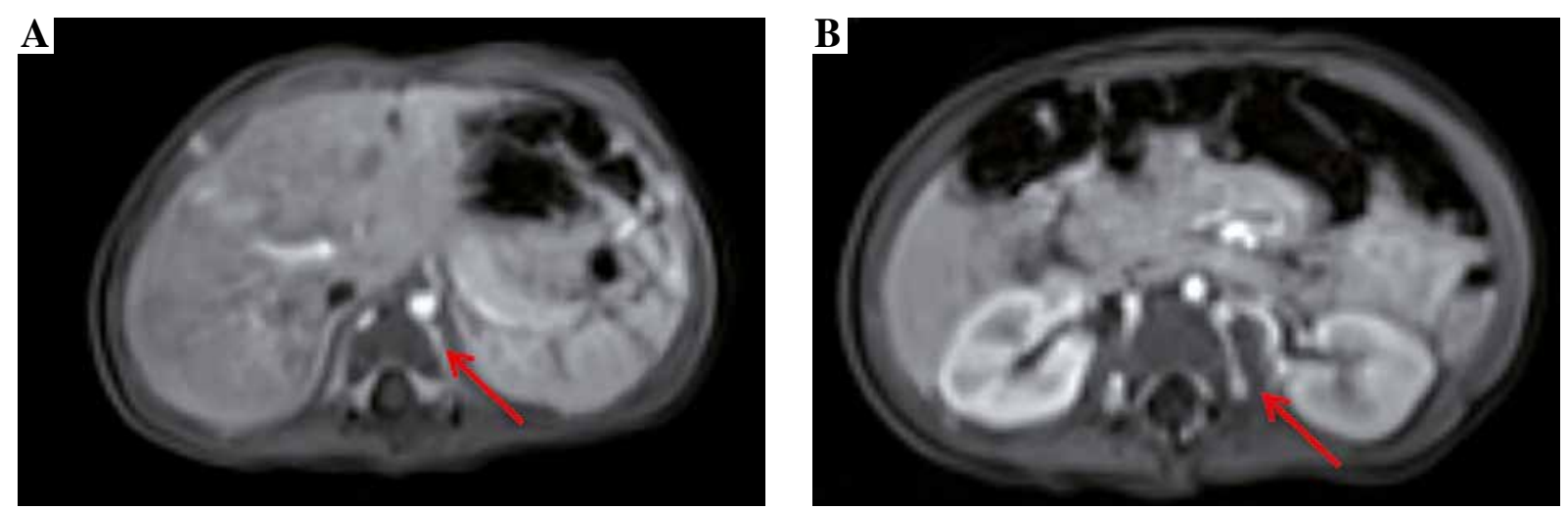

Fig. 2. Magnetic resonance of the abdomen. Common iliac veins and IVC without contrast signal; venous outflow from the lower extremities and from the kidneys to the paravertebral plexuses

Calcifications within the renal medulla are most often associated with metabolic disorders and indicate the need for extensive metabolic and genetic diagnostics. On the other hand, calcifications involving renal cortex indicate a history of necrosis (e.g., as a result of perinatal hypoxia or renal thrombosis) $[10,14,15]$.

In the described patient, no metabolic disorders that could increase the risk of precipitation of calcium salts in the renal parenchyma were found. As vitamin D hypersensitivity was suspected, which is usually associated with reduced activity of vitamin $D$ inactivating 24-hydroxylase (mutations in the CYP24Al gene), vitamin D supplementation was temporarily discontinued [15]. In the ultrasound scan, kidney lesions were not typical for any metabolic cause of nephrocalcinosis. Despite medullar location of the calcifications, thrombosis was suspected as the cause of observed lesions. Thrombosis was confirmed in the subsequent US and MRI. Although imaging studies did not clearly show the presence of thrombi in the renal veins, kidney lesions suggested a history of thrombotic process. It is difficult to clearly determine when massive thrombosis occurred. The presence of calcifications both in the kidneys and in the IVC lumen indicated that the event was distant in time; calcifications appear approximately 6 weeks after a thrombotic event [10]. Well-developed collateral circulation also supported the hypothesis on fetal thrombosis. On the other hand, high concentration of D-dimers found at six months of age could suggest that the thrombotic process was still active at that time. After a month of anticoagulation, D-dimer levels normalized. The described patient did not have the classic risk factors for thrombosis; the girl was born on time, there was no perinatal hypoxia, and no vessels were catheterized. No cause of congenital thrombophilia was found in the performed tests. The only detectable moment of possible fluctuations of fetal blood volume was acute appendicitis diagnosed in the mother at $16^{\text {th }}$ week of gestation. However, this condition cannot be clearly linked to a history of thrombosis in the fetus.

Table 2. Causes of calcifications within the renal parenchyma (nephrocalcinosis) according to [10] and [15] in own modification

\begin{tabular}{|c|c|}
\hline $\begin{array}{l}\text { Medullary } \\
\text { nephrocalcinosis }\end{array}$ & $\begin{array}{l}\text { 1. Prematurity (complex etiology associated with, among others, the use of loop diuretics) } \\
\text { 2. Tubulopathies with hypercalciuria, including Dent syndrome, Lowe syndrome, Bartter syndrome, familial } \\
\text { hypomagnesaemia with hypercalciuria and nephrocalcinosis, distal tubular acidosis, idiopathic hypercalciuria } \\
\text { 3. Endocrinopathies with hypercalciuria: primary hyperparathyroidism, Cushing's syndrome } \\
\text { 4. Hyperoxaluria: primary - type } 1,2 \text {, and } 3 \text {, intestinal, idiopathic } \\
\text { 5. Other PTH-independent causes of hypercalcemia: parathyroid hormone-secreting cancers (PTHrp), Williams } \\
\text { syndrome, sarcoidosis } \\
\text { 6. Sickle cell disease } \\
\text { 7. Drugs: loop diuretics, vitamin D (overdose and hypersensitivity), vitamins A and C, glucocorticoids } \\
\text { 8. Immobilization } \\
\text { 9. Beta-thalassemia } \\
\text { 10. Hypophosphatemic rickets } \\
\text { 11. Congenital enamel hypoplasia and nephrocalcinosis syndrome }\end{array}$ \\
\hline $\begin{array}{l}\text { Cortical } \\
\text { nephrocalcinosis }\end{array}$ & $\begin{array}{l}\text { 1. Renal cortical necrosis (e.g., after hypoxia, renal thrombosis) } \\
\text { 2. Chronic pyelonephritis } \\
\text { 3. Injuries } \\
\text { 4. Transplant rejection } \\
\text { 5. Hyperoxaluria }\end{array}$ \\
\hline
\end{tabular}


In rare cases, venous and arterial thrombosis may occur in the fetal period [7, 16-21], and reports of in utero venous thrombosis diagnosed in a patient with renal calcifications are available in the literature [14, 16]. Belgian authors described the case of renal vein and IVC thrombosis diagnosed in utero. Comparably to the girl discussed here, the thrombosis resulted in calcifications in the renal parenchyma, with development of collateral circulation bypassing the obstructed IVC fragment [16]. On the other hand, massive IVC thrombosis in utero can lead to fetal hypoxia, capillary damage, and protein loss into the interstitial space, resulting in non-immune fetal edema [20], kidney failure [11], and death [22, 23]. Underdevelopment or malformations of IVC are found in approx. $0.3 \%$ of people. It is believed that intrauterine or perinatal venous thrombosis may be responsible for some of the cases of IVC agenesis [21, 24, 25]. In our patient, the thrombotic process led to complete obliteration of IVC and iliac veins. The case reported here and a few literature reports $[14,16]$ suggest that even a massive venous thrombosis in the prenatal period may remain completely asymptomatic for a long time. Diagnosis of IVC and renal veins thrombosis in the prenatal period is difficult. Such features as large hyperechogenic kidneys, increased echogenicity in the inter-lobe veins, thrombus visible in the IVC, increased resistance index, or reversal of renal artery flow in Doppler scan may suggest renal vein thrombosis [11]. Diagnosis of venous thrombosis is also possible in fetal MR imaging [21].

The decision of anticoagulant therapy administration in the case of neonatal or infant venous thrombosis is made individually $[1,2]$. It is suggested that a transfontanellar ultrasound should be performed prior to the treatment to exclude active bleeding [10]. In most cases, the American Society of Hematology recommends unfractionated heparin (UFH) or low-molecular-weight heparin (LMWH) administration for 6 weeks to 3 months [1-3, 10]. In bilateral renal vein thrombosis resulting in acute kidney injury, the use of recombined tissue plasminogen activator (rtPA) is suggested, despite possible serious adverse effects of such a treatment $[1,3,10]$. Dosage and administration schedule for rtPA are available in the literature, and contraindications include recent surgery, intracranial bleeding or other active bleeding, convulsions, thrombocytopenia $\left(<100 \times 10^{3} / \mu \mathrm{l}\right)$, or hypofibrinogenemia $(<1 \mathrm{~g} / \mathrm{l})[3,10$, 13]. There are single case reports of successful local catheter-directed thrombolysis [26] or surgical thrombectomy in a newborn $[9,12]$. In the discussed case, due to stable clinical course and difficulty in determination of the time of thrombosis, it was decided to administer low-molecular-weight heparin. The treatment was well tolerated by the girl and no progression was observed.

Thrombosis of IVC and its branches may be associated with serious distant consequences [8]. Renal vein thrombosis may result in kidney cirrhosis (approx. 70\% of cases) and hypertension (approx. 20\% of cases). Ad- verse consequences for the kidney can occur regardless of the treatment [1-3]. In the case of bilateral thrombosis, the patient is at risk of developing chronic kidney disease (CKD) with all its consequences. In patients with CKD, post-thrombotic occlusion of IVC or iliac veins may be of great difficulty, when placing vascular catheters for hemodialysis or kidney transplantation [10]. IVC obstruction poses a risk of impaired blood outflow from the lower body and distant complications, including post-thrombotic syndrome (erythema, edema, varicose veins, distal vein thrombosis) $[9,21,27]$. There is no doubt that children who underwent a perinatal thrombosis involving IVC and renal veins require regular follow-up by a nephrologist, with an assessment of renal shape and size, renal function, microalbuminuria, and blood pressure. Moreover, patients after IVC thrombosis require accurate and periodic clinical evaluation for post-thrombotic syndrome of the lower extremities [3].

\section{Conclusions}

The differential diagnosis of calcifications in renal parenchyma (nephrocalcinosis) should include renal vein thrombosis. Even massive fetal and perinatal thrombosis can be asymptomatic due to high ability to form collateral circulation at the early stage of life.

\section{The authors declare no conflict of interest.}

\section{References}

1. Monagle P, Cuello CA, Augustine C, et al. (2018): American Society of Hematology 2018 Guidelines for management of venous thromboembolism: treatment of pediatric venous thromboembolism. Blood Adv 2: 3292-3316

2. Kenet G, Cohen O, Bajorat T, et al. (2019): Insights into neonatal thrombosis. Thrombosis Res 181S1: S33-S36

3. Resontoc LP, Yap H-K (2016): Renal vascular thrombosis in the newborn. Pediatr Nephrol 31: 907-915.

4. Reverdiau-Moalic P, Delahousse B, Body G, et al. (1996): Evolution of Blood Coagulation Activators and Inhibitors in Healthy Human Fetus. Blood 88: 900-906.

5. Karpatkin M, Lee M, Cohen L, et al. (2000): Synthesis of coagulation proteins in the fetus and neonate. J Pediatr Hematol Oncol 22: 276-280.

6. Pichler E, Pichler L (2008): The neonatal coagulation system and the vitamin $\mathrm{K}$ deficiency bleeding - a mini review. Wien Med Wochenschr 158: 385-395.

7. Szvetko A, Hurrion E, Dunn A, et al. (2014): Axillary artery thrombosis in a neonate in utero: a case report. Case Reports Pediatr 2014: 417147.

8. Kumar R, Kerlin BA (2017): Thrombosis of the abdominal veins in childhood. Front Pediatr 5: 188.

9. Häusler M, Hübner D, Delhaas T, et al. (2001): Long term complications of inferior vena cava thrombosis. Arch Dis Child 85: 228-233.

10. Rees L, Bockenhauer D, Webb NJA, Punaro MG (2019): Pediatric Nephrology. Oxford University Press, Oxford, UK. 
11. Kdous M, Khlifi O, Brahem M, et al. (2015): Extensive thrombosis of the inferior vena cava and left renal vein in a neonate. Case Reports Obstet Gynecol 2015: 569797.

12. Lee S, Ananth P, Boyd T, et al. (2014): Scuccessful surgical thrombectomy for neonatal IVC and bilateral renal vein thrombosis. J Ped Surg Reports 2: 176-179.

13. Niada F, Tabin R, Kayemba-Kay's S (2018): Spontaneus neonatal renal vein thromboses: should we treat them all? A report of five cases and a literature review. Pediatric Neonatol 59: 281-287.

14. Ranch D, Aigbe MO, Gorospe EC (2006): Prenatal calcification of the inferior vena cava and renal veins in a normal neonate. Scient Word J 6: 734-736.

15. Oliveira B, Kleta R, Bockenhauer D, et al. (2016): Genetic, pathophysiological, and clinical aspects of nephrocalcinosis. Am J Renal Physiol 311: F1243-F1252.

16. Rypens F, Avni F, Braude P, et al. (1993): Calcified inferior vena cava thrombus in a fetus: perinatal imaging. J Ultrasound Med 12: 55-58.

17. Wardle SP, Emmerson AJB (1996): Aortic arch thrombosis in a neonate with coarctation exposed to cocaine in utero. J R Soc Med 89: 524-525.

18. Knadler JJ, Zobeck M, Masand P, et al. (2019): In utero aortic arch thrombosis masquerading as interrupted aortic arch: a case report and review of the literature. Pediatr Cardiology 40: 658-663.

19. Oppermann M, Padberg S, Kayser A, et al. (2012): Angitensin-II receptor 1 antagonist fetopathy - risk assessment, critical time period and vena cava thrombosis as a possible new feature. Br J Cin Pharmacol 75: 822-830.

20. Weissmann-Brenner A, Ferber A, O'Reilly-Green C, et al. (2004): Inferior vena cava thrombosis presenting as non-immune hydrops in the fetus of woman with diabetes. Ultrasound Obstet Gynecol 23: 194-197.

21. Ramanathan T, Huges TMD, Richardson AJ (2001): Perinatal inferior vena cava thrombosis and absence of the infrarenal inferior vena cava. J Vasc Surg 33: 1097-1099.

22. Van der Vange N, Bruinse HW (1986): Hydrops fetalis associated with inferior vena cava thrombosis Eur J Obstet Gynecol Reprod Biol 21: 113-115.

23. Rudolph N, Levin EJ. (1977): Hydrops fetalis with vena caval thrombosis in utero. N Y State J Med 77: 421-423.

24. Debing E, Tielemans Y, Jolie E, et al. (1993): Congenital absence of inferior vena cava. Eur J Vasc Surg 7: 201-203.

25. d'Archambeau O, Verguts L, Myle J (1990): Congenital absence of inferior vena cava. J Belge Radiol 73: 516-517.

26. Khan JU, Takemonto CM, Casella JF, et al. (2008): Catheter-directed thrombolysis of inferior vena cava thrombosis in a 13-day-old neonate and review of literature. Cardiovasc Intervent Radiol 31: S153-S160.

27. Nikolova-Vlahova MK, Nikolov KV, Baleva MP, et al. (2015): Antiphospholipid antibodies in patients with upper-extremity deep vein thrombosis. Cent Eur J Immunol 40: 307-310. 